\title{
PROGRESSOS NOS ESTUDOS DE GEOMORFOLOGIA FLUVIAL URBANA AO FINAL DO SÉCULO XX
}

\author{
PROGRESS IN STUDIES OF URBAN FLUVIAL GEOMORPHOLOGY AT THE END OF THE TWENTIETH \\ CENTURY
}

\author{
Osvaldo Girão \\ Universidade Federal de Pernambuco (UFPE), Recife, PE, Brasil, osgirao@gmail.com \\ Antonio Carlos de Barros Corrêa \\ Universidade Federal de Pernambuco (UFPE), Recife, PE, Brasil, dbiase2001@terra.com.br
}

\section{RESUMO}

Os precursores da Geomorfologia Fluvial levaram em consideração condições ambientais pré-existentes de equilíbrio que viriam a ser alteradas como resultado de processos acelerados de erosão e/ou deposição de material sedimentar. Dentre os impactos causados por alterações em condições ambientais fluviais, o processo de urbanização constitui-se no que pode, por vezes, além de afetar áreas impactadas, ser transmitido tanto a montante quanto a jusante, até mesmo ao longo de cursos afluentes. Além de ações diretas sobre o canal, como ajustamentos no curso fluvial, ações indiretas como a impermeabilização de solos, promovem forte impactos aos sistemas fluviais. Para avaliar os progressos nos estudos da Geomorfologia Fluvial Urbana em fins do século passado, faremos a avaliação da evolução deste campo da Geomorfologia a partir dos trabalhos de Wolman (1967), Ebisemiju (1989), Whitlow e Gregory (1989) e Gregory, Davis e Dows (1992). Os autores em questão demonstraram a relevância dos estudos relativos à Geomorfologia Fluvial Urbana como subsídio a projetos voltados para o planejamento e gestão de bacias fluviais que sofrem um crescente processo de urbanização.

Palavras-chave: Processo de Urbanização, Alterações em Interflúvio, Impactos Ambientais, Geomorfologia Fluvial, Rios Urbanos.

\begin{abstract}
The forerunners of Fluvial Geomorphology took into consideration environmental conditions pre-existing balances which changed as a result of accelerated erosion and / or deposition of sedimentary material. Among the impacts of environmental changes on river conditions, the process of urbanization is on what can, sometimes, in addition to affecting the impacted areas, be transmitted upstream and downstream, and even courses along tributaries. In addition to direct actions to the channel, as adjustments in river course, indirect actions such as soil sealing, promote strong impacts on river systems. To assess progress in studies of Urban Fluvial Geomorphology at the end of the last century, we will assess the progression this field of Geomorphology based on work of Wolman (1967), Ebisemiju (1989), Whitlow and Gregory (1989) and Gregory Davis and Dows (1992). The authors in question have demonstrated the relevance of studies on Urban Fluvial Geomorphology as a subsidy for projects to planning and management of river basins suffering a growing process of urbanization.
\end{abstract}

Keywords: Process of Urbanization, Changes in the Interfluve, Environmental Impacts, Fluvial Geomorphology, Urban Rivers.

Artigo recebido para publicação em dezembro de 2014

Artigo aceito para publicação em abril de 2015

\section{INTRODUÇÃO}

Mudanças verificadas em ambientes de bacias hidrográficas têm como causas alterações no equilíbrio dinâmico dos elementos naturais que as compõem, bem como alterações derivadas de mudanças no uso e ocupação do solo. Apesar das crescentes alterações nos interflúvios nos últimos séculos, refletindo a 
extensiva e intensiva ação do homem sobre os ambientes fluviais, no século XX as atividades antrópicas passaram a se constituir não só em um fator degradante para o meio natural, mas também de aceleração de alterações nas bacias fluviais, levando a intensas e impactantes modificações na paisagem em pequenos intervalos de tempo.

Segundo Cunha e Guerra (1996), e Gregory (2006), os impactos das atividades antrópicas em ambientes de bacias hidrográficas podem ser de dois tipos: diretos, quando são executadas obras de engenharia no interior de cursos fluviais, como ampliação da largura do leito, retificação e canalização do canal, construção de barragens e desvios, que causam mudanças na dinâmica de canais fluviais; e indiretos, quando os impactos são originários da urbanização que, inicialmente, leva ao desmatamento e, posteriormente, a mudanças no uso e ocupação da terra. Na dependência da amplitude e intensidade do processo de urbanização, ocorrem também modificações significativas nos regimes de precipitação e temperatura e, conseqüentemente, no ciclo hidrológico. Acrescem-se a essas mudanças na rede de canais; transferência de água entre bacias; criação de superfícies impermeáveis e modificações nas propriedades e estrutura dos solos em decorrência da exposição da superfície dos mesmos, especialmente em locais de construção, causando tais impactos mudanças nos interflúvios e na morfologia e hidrologia do canal fluvial.

Como efeitos indiretos, os impactos da ação antrópica derivada da urbanização causam mudanças na capacidade do canal e nos processos fluviais, refletindo nos processos de erosão, transporte e deposição, que levam ao aumento do pico de descarga e ao assoreamento, não só pelo aumento de material sedimentar disponível, mas também pela adição do lixo urbano, que podem contribuir para a majoração da recorrência de eventos de enchentes.

Nas últimas quatro décadas do século XX, os efeitos da alteração do uso e ocupação do solo em interflúvios devido à expansão das cidades levaram a modificações do escoamento superficial, e seus posteriores impactos sobre o sistema fluvial. Tais transformações mereceram grande atenção dos estudiosos da Geomorfologia Fluvial, estando em sua maior parte relacionadas a rápidas mudanças no sistema fluvial, derivadas de medidas de regulação objetivando melhorias na drenagem, redução da 
recorrência de enchentes ou mesmo controle da erosão das margens (WHITLOW e GREGORY ,1989).

Do exposto, constata-se a relevância dos estudos relativos à Geomorfologia Fluvial Urbana como subsídio a projetos voltados para o planejamento e gestão de bacias fluviais que sofrem um crescente processo de urbanização. O número de estudos desse campo da Geomorfologia cresceu concomitantemente às demandas dos grandes centros urbanos, coincidindo seu "nascimento" com o crescimento do número de cidades, bem como o adensamento populacional.

Buscando avaliar as origens e progressos dos estudos da Geomorfologia Fluvial Urbana, a partir do final da década de 1960 até o início da década de 1990, o artigo em pauta está norteado nos trabalhos de Wolman (1967), Ebisemiju (1989), Whitlow e Gregory (1989) e Gregory, Davis e Dows (1992).

Constituindo-se em marcos do desenvolvimento da Geomorfologia Fluvial Urbana, a avaliação interrelacional destes trabalhos proporcionou uma revisão evolutiva desse campo de estudo da geomorfologia, bem como uma síntese da dinâmica dos progressos realizados nesse segmento da ciência geomorfológica na segunda metade do século XX, tomando-se por base os seguintes parâmetros de análise dos estudos: objetivos, metodologias, análises dos dados, hipóteses e conclusões.

Apesar dos avanços consideráveis dos parâmetros aludidos anteriormente em estudos realizados já em fins do século XX e na primeira década do século XXI, acreditamos que os quatro estudos considerados foram basilares para o desenvolvimento das pesquisas geomorfológicas fluviais urbanas contemporâneas, que passaram a enfatizar objetivos visando a contribuição para com ações de planejamento e gestão de ambientes fluviais em áreas urbanas a partir daqueles estudos pioneiros.

\section{Objetivos dos Estudos}

Os objetivos dos estudos em questão evoluíram seguindo uma lógica iniciada com trabalhos relativos a aspectos das conseqüências de mudanças no uso da terra à avaliação do ajuste natural de um canal às 
mudanças derivadas de uma extensiva urbanização. Percebe-se que os objetivos, inicialmente generalistas e calcados no preceito causa-efeito, evoluíram ao longo das décadas de 1970 e 1980 , buscando o reconhecimento não só das conseqüências das mudanças, mas também a universalização de formas e métodos de identificação de alterações causadas pela expansão urbana.

No caso de Wolman (1967), o autor não especifica no texto qual o objetivo do estudo, entretanto podese identificar a busca por avaliar o Ciclo de Mudanças na dinâmica do interflúvio e do canal derivado de distúrbios nas condições naturais prevalecentes, principalmente a partir do desenvolvimento de um sítio urbano em uma bacia hidrográfica, tomando como área de estudo a costa Atlântica a Nordeste dos Estados Unidos. No estudo em pauta, evidencia-se a preocupação do autor com as variadas formas de uso e ocupação da terra (permanência de cobertura florestal, atividades de cultivo e construção de edificações e vias de acesso) como fator principal e determinante para as alterações no interflúvio e no canal fluvial.

Já no estudo de Ebisemiju (1989) não há tantas referencias às condições naturais predominantes anteriormente como demonstrou Wolman (1967) em sua pesquisa, sendo objetivo do segundo autor a avaliação das modificações nos canais naturais devido à urbanização nos trópicos úmidos, bem como analisar e discutir a morfologia da corrente dos canais face a um rápido crescimento urbano no Sudoeste da Nigéria.

Ebisemiju sobressaiu-se como autor de uma das principais referências, se não a principal até então, nos estudos geomorfológicos fluviais urbanos realizados em países tropicais, uma vez que seus estudos são desenvolvidos em uma zona urbana com características fisiográficas diferenciadas, no referente a índices médios anuais de precipitação pluviométrica, intensidade das chuvas, temperatura e cobertura vegetal, se comparadas com as condições do meio natural prevalecentes nos inúmeros estudos realizados até o final da década de 1980 no continente europeu e nos Estados Unidos.

A mudança nos objetivos propostos é evidenciada também a partir do estudo realizado por Whitlow e Gregory (1989) que avaliaram a dinâmica evolutiva que um canal desenvolveu, de uma situação de 
descontinuidade para uma de continuidade, mas essencialmente "feita pelo homem" no período de 1891 a 1984, e o ajuste natural do sistema de canal para o aumento do pico de descarga, resultado da extensiva área de construção derivada de uma expansão urbana no Zimbábue.

Os objetivos de Whitlow e Gregory (1989) demonstraram a preocupação dos autores com a evolução dos efeitos do desenvolvimento urbano e as mudanças no canal e sobre terras pantanosas, localmente denominadas de "dambo", em uma parte menor da bacia. Essas terras úmidas vêm desacelerando o desenvolvimento urbano e, concomitantemente, exibindo indícios crescentes de secagem como um resultado da canalização e outras formas de distúrbios.

A transformação temporal dos objetivos nos estudos fluviais urbanos é ilustrada a partir do artigo de Gregory, Davis e Dows (1992), que enveredam por novos objetivos, no caso, demonstrar, através de estudos realizados no centro-sul da Inglaterra, os caminhos em que mudanças no canal fluvial podem ser identificadas e sugerir métodos para a identificação de mudanças no canal que possam ser aplicados em outros lugares.

Ainda em relação ao estudo realizado por Gregory, Davis e Dows (1992), podemos constatar avanços nas temáticas relativas à Geomorfologia Fluvial Urbana devido à mudança de foco nos objetivos, que até fins da década de 1980 tinham como meta a investigaçãosobrea natureza das mudançasno canal como conseqüencia do desenvolvimento urbano, regulação de fluxode canalizaçãoe reflexos demudanças no uso e ocupação da terra (Gregory 1987). Contudo, objetivos relativos ao "como" ou "por que" as mudanças aconteciam, e onde elas estavam localizadas, e durante quanto tempo elas poderiam ocorrer, caracterizaram as novas contribuições propostas a partir do artigo de Gregory, Davis e Dows (1992).

\footnotetext{
1 Terrenos presentes na zona subsaariana africana. São áreas úmidas muito ligeiramente inclinadas e rasas, sem apresentar canais de rios permanentes; são caracterizadas por serem preenchidas com areias e argilas, sendo os solos férteis e úmidos, servindo como pastagem na estação seca (MAYHEW, 2004).
} 
O período do final da década de 1980 ao início da década de 1990 constituiu-se em um "divisor de águas" nos objetivos dos estudos fluviais urbanos, que até então buscavam avaliar as mudanças verificadas no canal e no interflúvio da bacia hidrográfica. A preocupação em evidenciar procedimentos e métodos de identificação de alterações na dinâmica fluvial urbana demonstra o objetivo de disseminação das pesquisas neste campo que, a partir do aumento das preocupações relacionadas ao meio ambiente ao longo da década de 1970, e principalmente da década de 1980, veio a contribuir para a crescente preocupação com políticas públicas voltadas para o meio ambiente, e mesmo voltadas à mitigação dos impactos causados pela expansão e intensificação da malha urbana.

Os objetivos enunciados nos diferentes artigos tomados como referência para a construção deste trabalho seguiram uma transformação de acordo com o grau de preocupações das sociedades para com o meio ambiente. Desde simples avaliações de conseqüências de mudanças do uso e ocupação do solo para o canal e para o interflúvio, a preocupações com desequilíbrios na dinâmica não só urbana, mas também com "espaços naturais" circunvizinhos de interesse econômico e ambiental, como no caso do estudo das áreas de dambo no Zimbábue, demonstrando a relevância dos objetivos dos estudos fluviais urbanos contemporâneos para o estabelecimento de relações sócio-econômico-ambientais sustentáveis.

\section{Metodologias dos Estudos}

As metodologias utilizadas nos estudos de Geomorfologia Fluvial Urbana passaram por significativas transformações ao longo das décadas de 1980 e 1990. Havendo sido inicialmente focadas sobre as transformações históricas ocorridas nos interflúvios e vales durante a década de 1960, ao longo dos 20 anos posteriores as abordagens passaram a priorizar uma crescente interação entre trabalhos de gabinete e de campo, sendo esses últimos reconhecidos como de grande relevância como procedimento metodológico dos estudos geomorfológicos fluviais.

O trabalho de Wolman (1967) apresentou as seguintes práticas metodológicas: Evidências de mudanças históricas; estimativas; observações periódicas (monitoramento); medições 
contemporâneas; estudos de sedimentos em grandes galerias e comparações de fotografias (periodização).

Percebe-se nos procedimentos metodológicos do autor um misto de metodologias ora de caráter avaliativo analítico, ora de caráter de aferição empírica. No tocante aos avaliativos analíticos tem-se como exemplo, a avaliação do Ciclo de Mudanças de uso da terra para a região Meio-Atlântica dos EUA, apresentado por meio de evidências históricas sem referências concretas, além de algumas estimativas sem indicação de autor ou fonte bibliográfica. Entretanto, a utilização de metodologias de aferição empírica como as observações e medições periódicas de aspectos indicadores de mudanças no equilíbrio dinâmico do canal e interflúvio, tais como a avaliação da carga de sedimentos depositados em galerias e mesmo a comparação de fotografias de um canal, remetem o estudo de Wolmam a uma análise mais robusta das alterações registradas em sua área de estudo.

Já Ebisemiju (1989), passados mais de 20 anos desde o clássico trabalho do Wolmam (1967), utilizou-se de uma vasta quantidade de métodos e procedimentos que surgiram e evoluíram ao longo desse período.

Quatro métodos foram usados para identificar mudanças no canal:

- Método Dedutivo, com monitoramento de mudanças no canal e marcos locais;

- Através do tempo, em cursos sujeitos a modificações;

- O uso do regime teórico ou relacionamento similar estabelecido entre forma de canal, água, e carga de sedimento;

- Técnica de interpolação espacial com envolvimento de cada uma comparação de correntes adjacentes, do que é modificado ou não, ou comparação ao longo de cursos individuais cujas partes superiores são naturais e à jusante pareçam ter sido modificadas.

Além dos métodos citados, foram efetivados os seguintes procedimentos: 
- Seções transversais preenchidas dos cursos dos canais foram levantadas, bem como o número de estações ao longo do curso principal em cada uma das bacias de drenagem;

- Também foram levantados os parâmetros geométricos do canal derivados de medidas de largura, média de profundidade, área de seção transversal ou capacidade do canal, proporção da forma e raio hidráulico;

- Os gradientes das encostas do leito do canal foram medidos com o nível de Abney na seção transversal, e os sedimentos do perímetro do canal (leito e margem) foram também coletados para análise textural.

Percebe-se que a utilização de um dos métodos de avaliação de mudanças realizado por Wolmam em 1967, reflete a relevância do trabalho deste autor para os estudos fluviais urbanos, que foi posteriormente aperfeiçoado por Ebisemiju (1989). Ainda em Ebisemiju (1989), o caráter avaliativo através do tempo e da interpolação espacial ganha importância a partir da diversidade temporal e espacial de mudanças verificadas tanto no interflúvio como no interior do próprio canal.

No referente aos procedimentos metodológicos, Ebisemiju utiliza-se efetivamente dos progressos verificados nas últimas décadas nos trabalhos de campo em estudos fluviais urbanos, sendo os levantamentos de seções transversais, parâmetros geométricos dos canais, dos gradientes das encostas, bem como a análise textural dos sedimentos do leito e margens, comprovados avanços conjugados ao aprofundamento das avaliações de mudanças, retratando a importância adquirida pelos procedimentos de campo na identificação de alterações na dinâmica da morfologia fluvial.

No estudo realizado por Whitlow e Gregory (1989) nas áreas de Dambos no Zimbábue, percebe-se a que a utilização dos dados de precipitação pluviométrica do Manual Climático do Zimbábue foi de grande importância durante o estudo, tratando-se a área em questão de terras pantanosas que resguardam grandes quantidades de água precipitada, o que se constituiu em um avanço nos estudos fluviais urbanos, que até então pouca importância davam à distribuição anual das precipitações em bacias hidrográficas. 
Em Whitlow e Gregory (1989) constata-se uma ampla análise temporal efetivada a partir de registros na forma de mapas recentes e fotografias aéreasque foram usados para reconstruir as mudanças da rede do canal, nesse caso, no período de 1891 a 1978. Estudos de dados relativos à bacia foram descobertos com razoável consistência de registros históricos, adicionados a observações geraisde campo em 1984. Avaliações na rede do rio foram realizadas em 6 seções para propor a descrição das principais mudanças no sistema do canal. Mudanças no uso da terra e na rede de estradas foram avaliadas a partir das fotografias aéreas. Áreas construídas e de dambos foram delimitadas em um mapa base a 1:10.000 e estimou-se a área de vários tipos de uso da terra para cada um dos anos.

No estudo de Whitlow e Gregory tem-se uma grande quantidade de procedimentos metodológicos, refletindo a complexidade de estudos realizados em uma área pantanosa sob expansão urbana, mas que também revela a multiplicidade e aprofundamento de procedimentos metodológicos atrelados aos estudos da Geomorfologia Fluvial Urbana em fins da década de 1980.

Apesar da utilização pelos autores anteriormente citados de evidências históricas como forma de identificação de mudanças na planície de um canal, foi no trabalho de Gregory, Davis e Dows (1992) que o uso de técnicas históricas teve maior ênfase nas análises de mudanças. Os chamados métodosou técnicas históricas envolvemcomparação damorfologiapresente comregistros de origemdatadas do passado.

A utilização de mapas ou imagens de sensoriamento remoto de diferentes datas para estabelecer mudanças na planície do riacho Monks, a comparação da morfologia contemporânea com as que foram registradas por dados cartográficos prévios, bem como a comparação de estudos topográficos anteriores de seções transversais do canal com estudos atuais de algumas localidades, foram procedimentos amplamente utilizados pelos autores em questão.

Para Gregory, Davis e Dows (1992), a utilização de indicadores de pesquisas de campo para canais contemporâneos, combinados com o uso de métodos históricos, oferece três principais procedimentos para indicar ajustamento morfológico do canal, sendo esses: as características morfológicas do canal, 
os indicadores da vegetação e as mudanças derivadas de estruturas existentes no interior do canal, como pontos (vide Quadro 1).

Tais procedimentos proporcionaram a formulação de um estudo da distribuição espacial das mudanças verificadas no riacho Monks, sendo tal metodologia uma importante contribuição para um eventual projeto de planejamento e gestão que busque um re-equilíbrio da dinâmica fluvial de um canal afetado por influências de um ambiente urbano.

\begin{tabular}{|c|c|c|c|c|c|c|c|c|c|}
\hline \multirow{2}{*}{ Trechos } & \multirow{2}{*}{$\begin{array}{c}\text { Número } \\
\text { de } \\
\text { Seções }\end{array}$} & \multicolumn{4}{|c|}{ Larguras Médias (m) } & \multicolumn{4}{|c|}{$\begin{array}{c}\text { Taxa de mudança nas larguras do } \\
\text { canal (m) }\end{array}$} \\
\hline & & $\begin{array}{c}1866- \\
96\end{array}$ & 1933 & 1951 & 1991 & $\begin{array}{l}1866- \\
1991\end{array}$ & $\begin{array}{r}1866- \\
1933\end{array}$ & $\begin{array}{c}1933- \\
51\end{array}$ & $\begin{array}{c}1951- \\
91\end{array}$ \\
\hline $\begin{array}{l}\text { Canal natural à } \\
\text { montante de } \\
\text { urbanização }\end{array}$ & 12 & 3,51 & 3,60 & 3,58 & 3,56 & 1,01 & 1,02 & 0,99 & 1,01 \\
\hline $\begin{array}{l}\text { Canal natural à } \\
\text { montante próximo } \\
\text { de pontes }\end{array}$ & 4 & 3,50 & 3,56 & 3,88 & 3,92 & 1,12 & 1,02 & 1,09 & 1,01 \\
\hline $\begin{array}{l}\text { Canal natural } \\
\text { ressecado à jusante } \\
\text { da urbanização }\end{array}$ & 7 & 2,95 & 3,02 & 5,00 & 6,13 & 2,07 & 1,02 & 1,66 & 1,23 \\
\hline $\begin{array}{l}\text { Canal natural à } \\
\text { jusante } \\
\text { urbanização }\end{array}$ & 7 & 3,89 & 3,93 & 4,79 & 4,87 & 1,25 & 1,25 & 1,22 & 1,02 \\
\hline $\begin{array}{l}\text { À jusante da } \\
\text { urbanização } \\
\text { próximo de pontes }\end{array}$ & 4 & 3,82 & 3,78 & 5,75 & 5,80 & 1,52 & 0,99 & 1,52 & 1,01 \\
\hline $\begin{array}{l}\text { À jusante de toda a } \\
\text { urbanização }\end{array}$ & 8 & 4,10 & 3,67 & 4,25 & 6,30 & 1,54 & 0,90 & 1,16 & 1,48 \\
\hline Todos os dados: & 42 & 3,63 & 3,59 & 4,38 & 4,98 & 1,38 & 1,03 & 1,23 & 1,14 \\
\hline
\end{tabular}




\begin{tabular}{l|l|l|l|l|l|l|l|l|l}
\hline Médias & & & & & & & & & \\
\hline Desvio Padrão & & $(0,86)$ & $(0,71)$ & $(1,07)$ & $(1,13)$ & & & \\
\hline
\end{tabular}

Quadro 1. Comparação da largura do canal do riacho Monks derivada de mapas topográficos de três períodos como resultados da pesquisa de campo em 1991 (GREGORY, DAVIS e DOWS, 1992, p. 304).

Assim, percebe-se os importantes avanços verificados nas metodologias utilizadas em quase 30 anos de estudos fluviais urbanos, passando de uma fase inicial de monitoramento de mudanças a uma avaliação mais consistente dos processos que ocorrem não só no interflúvio, mas também no interior do canal, que resultou em estudos cada vez menos avaliativos e mais corretivos, e mesmo propositivos à prevenção para alterações na dinâmica fluvial.

\section{Análise dos Dados dos Estudos}

A análise de dados realizada por Wolman (1967), inicialmente, remete ao Ciclo de Urbanização no Interflúvio, demonstrado através do clássico gráfico referente às mudanças de uso da terra na região Meio Atlântica, na costa leste dos Estados Unidos (Figura 1). Apesar da importância da análise acerca da correlação do tipo de uso da terra (floresta, lavoura, pastagem/pecuária e construção) com a produção de sedimentos, o autor desconsidera uma provável reativação de atividades de construção por ocasião de uma expansão na área urbanas após o pico da fase de crescimento.

No estudo de Wolman, o autor realiza uma análise de produção de sedimentos nas bacias de drenagem por meio de dados relativos à área de drenagem (em milhas quadradas; produção de sedimentos em toneladas quadradas e milhas ao ano) e uso da terra. Entretanto, o autor desconsidera outros fatores além do uso da terra, considerado nesse caso como fator determinante, tais como: condições climáticas, sazonalidade das precipitações pluviais, litologia, tipos de solos presentes nas bacias, dentre outros. Tal aspecto leva a conclusões imediatistas e não reflete a complexidade da dinâmica de uma bacia de drenagem.

De uma forma geral o trabalho desenvolvido por Wolman em 1967 demonstrou variados avanços nos estudos de leitos fluviais, apresentando análises de vários dados obtidos ao longo do estudo. Todavia, 
percebe-se que as análises não foram aprofundadas e correlacionadas com outros dados referentes às mesmas áreas em análise, reflexo de uma percepção não sistêmica dos variados fatores atuantes na dinâmica das bacias fluviais.

Ebisemiju (1989), inicialmente, chama a atenção para a escassez de dados da capacidade do canal de pequenos rios para análises comparativas. O autor atenta para o fato de que quando os dados para tais análises são avaliados, as comparações devem ser abordadas cautelosamente por conta da morfologia de um canal ser controlada por vários fatores, dentre os quais: clima, descarga do rio, sedimentos do perímetro do canal, características físicas da carga do rio, litologia, e cobertura vegetal, sendo essas interações freqüentemente complexas.

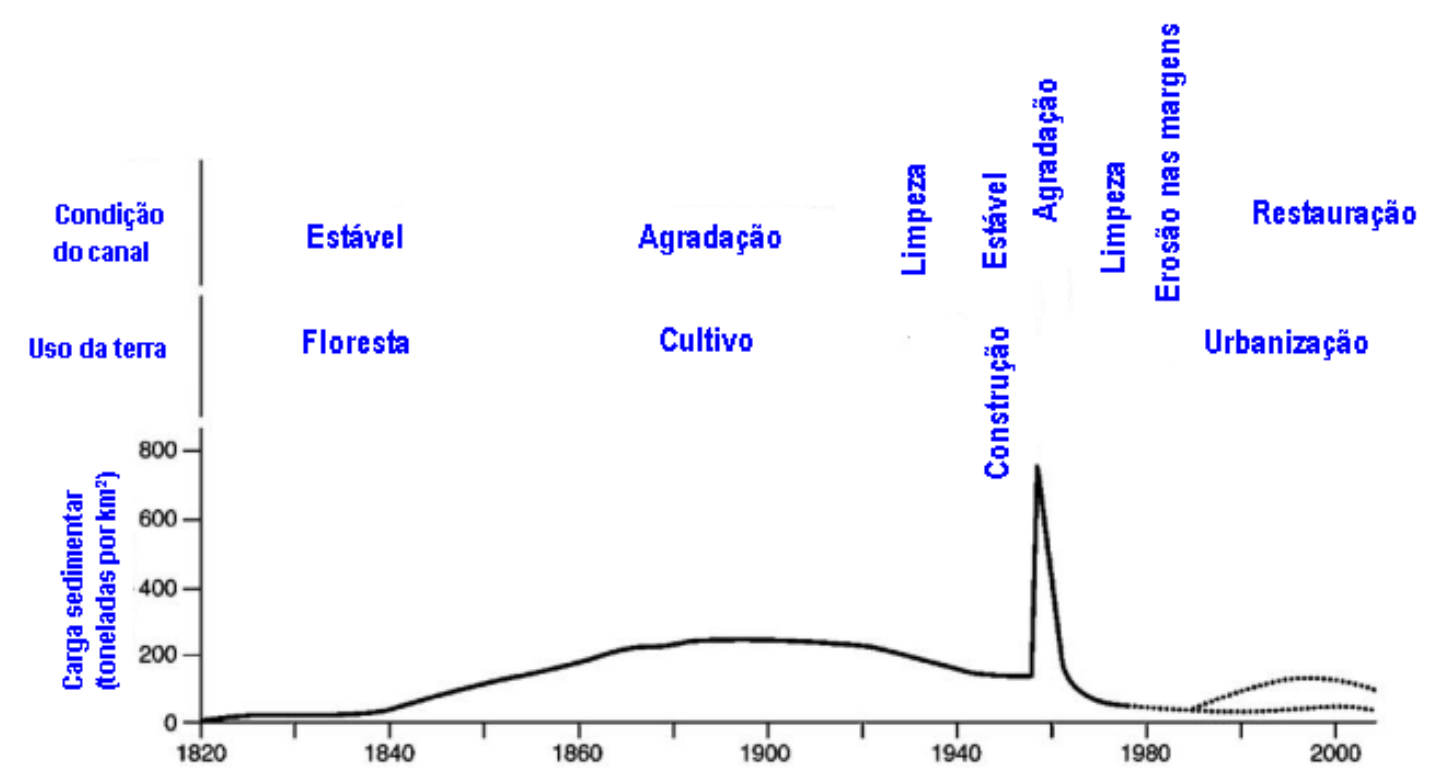

Figura 1. Ciclo de Mudanças de uso da terra para a região Meio Atlântica, Nordeste dos Estados Unidos (adaptado de WOLMAN, 1967 apud GREGORY, 2006).

Análises comparativas para averiguação da densidade de drenagem e capacidade do canal entre regiões temperadas e tropicais, assim como entre áreas urbanas e rurais em variados segmentos do curso, se constitui em um marco na análise de dados de bacias fluviais em áreas urbanas. Ademais, tal aspecto de análise introduz a necessidade da avaliação não só dos fatores diretamente relacionados com a planície do canal principal de uma bacia, mas também dos fatores que indiretamente atuam de forma diferenciada através de complexas correlações espaciais e mesmo sazonais, tendo as diferenciações dos elementos climáticos atuação marcante sobre a dinâmica de bacias fluviais. 
Outra importante contribuição na análise dos indicadores de mudanças no canal feita por Ebisemiju (1989) é a relativa importância que autor atribui aos efeitos da erosividade dos solos tropicais, principalmente quando desnudos e, conseqüentemente, mais susceptíveis à erosão, propiciando um interessante link entre a intensidade das chuvas tropicais (erodibilidade) com o índice de erosividade dos solos que, juntamente com resíduos urbanos (principalmente lixo) e a ação das fortes lâminas de água derivadas das chuvas, produz uma quantidade considerável de carga sedimentar no canal, levando o autor a identificar índices anuais de agradação e acreção lateral.

Tal análise proporciona grande contribuição à avaliação interrelacional entre os fatores fisiográficos da bacia em questão e as alterações causadas pelo processo de ocupação urbana ocorrido desde o final do século XIX, levando a uma análise evolutiva dos aspectos espaço-temporais dos principais indicadores de mudanças do sistema fluvial.

No caso específico desse estudo, a avaliação dos dambos, ou terras pantanosas, que originalmente ocupavam aproximadamente $25 \%$ da bacia do rio Avondale, constituindo-se em área de grande importância para o sistema de drenagem e mesmo como área agrícola, reitera a preocupação dos autores com a necessidade da manutenção, ou ao menos diminuição de ações impactantes, sobre uma parte que, outrora, chegou a ocupar praticamente $1 / 4$ do ecossistema originário da bacia do rio Avondale.

Além da preocupação com as conseqüências que a expansão urbana vem causando nas áreas de dambos, a análise dos dados evidencia que a ocupação pode levar a numerosos problemas em uma área urbana. Por exemplo, nos anos iniciais do assentamento de Harare (década de 1890) o alagamento sazonal dos pântanos representava o principal obstáculo para o deslocamento de pessoas e animais, bem como um local ideal para procriação de mosquitos e outros insetos que levavam doenças aos assentados. Além disso, os solos dos dambos não eram fáceis de serem drenados e afetavam a disposição de água de esgoto, especialmente onde havia sistemas de tanques sépticos, não podendo operar em área com nível de água elevada. Ademais, os solos das áreas de dambo não propiciam boas 
fundações para construção, particularmente por causa da expansão e contração das argilas negras que ocorrem nos solos da bacia do Avondale. Conseqüentemente, em Harare as áreas de dambos têm sido evitadas para a expansão residencial, sendo deixadas como áreas abertas ou usadas para campos de golf. Os autores deixam transparecer que tanto os dambos quanto a expansão urbana sofrem alterações derivadas da inexistente, ou ineficiente gestão do processo de ocupação da área em foco.

Mas o grande avanço na análise dos dados produzidos nesse estudo é a avaliação evolutiva da seqüência do desenvolvimento para 6 seções estudadas. As análises efetivadas ao longo da pesquisa revelam, por exemplo, a falta de características de canal no Avondale no princípio do século XX, com desempenho do canal descontínuo dentro de uma área de "dambo" até 1940, aspectos evidenciados através da avaliação da seção A, que ainda leva a concluir que o Avondale torna-se uma forma fluvial permanente a partir de meados dos anos 1950, sendo provável que ele tenha sido originalmente um extenso dambo em um vale fundo.

O que se constata na avaliação das outras 5 seções avaliadas no estudo é uma profunda retrospectiva dos estágios evolutivos por que passou o Avondale ao longo de mais de 100 anos, tendo nas evidências documentais, registros históricos, mapas e fotografias aéreas um poderoso aparato técnico que, conjugado às observações e procedimentos contemporâneos, proporcionaram um estudo avaliativo das conseqüências para a morfologia do canal e dos dambos derivadas de obras de alinhamento, realinhamento, aprofundamento e canalização do canal, bem como da expansão e intensificação das atividades ligadas ao crescimento urbano na bacia do Avondale.

Assim, as avaliações de mapas recentes e fotografias aéreas, bem como as análises dos dados extraídos de registros e observações e procedimentos contemporâneos mostram que anteriormente ao desenvolvimento urbano o dambo era extenso, localmente muito úmido e descontínuo; sendo que em algum tempo o canal passou a ser definido de forma incipiente. Com a ampliação da área construída do núcleo urbano de Harare sobre a bacia, bem como com a construção de estradas que cruzam as áreas de dambo, este foi progressivamente modificado. 
No estudo constatou-se que o sistema do canal principal do Avondale é resultado de mudanças deliberadas e acidentais e que este forma uma rede contínua estendendo-se por toda parte da bacia com drenagem superficial e subterrânea. Isto contrasta com as condições dentro da bacia pré-urbanizada quando existiu um canal descontínuo em uma depressão pantanosa e o escoamento superficial se dava provavelmente na forma de fluxos superficial difusos. Ademais, a importância hidrológica da área de dambo tem sido reduzida, uma vez que esta tem declinado de aproximadamente $25 \%$ da bacia préurbanizada para 10\% em 1978, com muito dessa área permanecendo agora localizada na parte baixa da bacia. Além disso, ultimamente os dambos são sujeitos a periódicas queimadas e cortes, particularmente para controlar as espécies de mosquitos durante a estação úmida. Istolevou, com o passar dos anos, a secá-los, e certamente tem reduzido sua capacidade para armazenar água, além de outros desequilíbrios de menor importância.

O grande avanço no estudo realizado por Whitlow e Gregory (1989) consiste em sua análise interrelacional, onde são enfocados os fatores típicos da área de interflúvio (estrutura geológica, aspectos climáticos, pedologia, geomorfologia), bem como os fatores diretamente relacionados com a dinâmica do interior do canal fluvial (canal natural e/ou retificado, contribuição de fluxo superficial de áreas urbanizadas e influência da cobertura vegetal sobre as margens), formulando um estudo consistente e com caráter preventivo a partir da identificação de aspectos relativos a conseqüências das alterações da dinâmica fluvial.

Em Gregory, Davis e Dows (1992), os dados são analisados a partir de correlações em canais fluviais em áreas florestadas, onde há uma série de indicadores para identificar uma ampliação do canal. Tais indicadores incluem casos onde há solapamento de margens, exposição de raízes de árvores ou árvores inclinadas ligando os lados opostos do canal ou onde as árvores foram localizadas de fato dentro do canal, deixando claro os indicadores de alargamento do canal.

Evidência da erosão em um local pode indicar mudanças autogênicas pela migração natural das margens do canal, ou ainda um alargamento do canal resultante de mudanças de ordem alogênica (geradas por fatores externos ao canal) originárias de alterações do regime climático e hidrológico, ou 
devido às atividades humanas. Tais autores diversificam as possibilidades de causas potenciais das mudanças verificadas no canal, desde mudanças naturais inerentes aos patamares de equilíbrio do próprio canal, a mudanças induzidas por alterações dos fatores naturais ou antrópicos atuantes sobre o sistema fluvial.

Um fato interessante nas análises do estudo em questão é o relevante papel que a cobertura vegetal arbórea próxima às margens representou para os autores, que chegaram a verificarárvores com crescimento originalmente nas margens do canal e que passaram a servir como marcos para ilustrar o subseqüente retrocesso da margem ou acumulação, sendo ainda evidenciados casos de árvores que estavam crescendo dentro do leito do canal.

Análises realizadas em 39 localidades ao longo do riacho Monks permitiu-se chegar ao resultado de mudanças no canal, usando-se estimativas de indicadores selecionados. Para 31 dessas localidades, onde o alargamento tem ocorrido, as medidas feitas nas seções transversais ilustram que o crescimento não ocorreu uniformemente e que as quantidades de mudanças podem não ser igualmente distribuídas ao longo do canal. Em contrapartida, para 8 locais foi notado que houve uma clara diminuição do leito do canal. Tais procedimentos revelam a variabilidade e complexidade de mudanças ocorridas no interior de um canal resultante de inúmeros fatores que levam ao alargamento ou retração de seções transversais.

Por exemplo, os autores revelam que canalizações próximas a pontes freqüentemente permitem a formação de obstáculos de sedimentos e detritos, desenvolvidos imediatamente à jusante e, em alguns períodos, à montante das pontes, ratificando o fato que mudanças na dinâmica do fluxo dos sedimentos devido a pontes existem e podem ser associadas com canais urbanizados.

A vegetação, em estruturas do canal, e outros indicadores, podem levar a estimativas do valor do alargamento do canal ou contração do mesmo, conforme se percebeu pelos dados relativos as 39 seções avaliadas. Para ampliar tais observações, é desejável estabelecer uma distribuição espacial específica do ajustamento do canal e relacioná-la com a ocorrência de influências urbanas. 
A grande contribuição das análises realizadas por Gregory, Davis e Dows (1992) consiste na revelação de que é possível que o ajustamento de um canal não aconteça de forma uniforme ao longo do mesmo. Comparativamente, poucos estudos têm referências ao detalhamento dos caminhos através dos quais as mudanças do canal variam espacialmente, mas estudos recentes têm mostrado como tais variações podem estar relacionadas às variações nas características e localização da urbanização, presença de sedimento no leito e margens do canal, e tempo decorrente desde o início da urbanização.

\section{Hipóteses dos Estudos}

Para Wolmam (1967) os processos de urbanização constituem-se no maior causador de distúrbios nas condições prevalecentes no interflúvio. A seqüência de mudanças com o desenvolvimento urbano é refletida em alterações marcantes nas formas de equilíbrio, e pode resultar no eventual estabelecimento de uma nova condição de equilíbrio, sendo que os processos ou ciclos de urbanização no interflúvio, refletem-se nos canais fluviais de uma região em três estágios:

1. Uma estabilidade inicial ou condição de equilíbrio em que a paisagem pode ser primariamente agrícola ou predominantemente florestal;

2. Um período de construção durante o qual o solo é exposto, e predispondo-o à erosão;

3. Um estágio final que consiste de uma nova paisagem urbana dominada por ruas, telhados, calhas e esgotos.

Para o autor as mudanças no interflúvio são acompanhadas por mudanças nas características do canal já durante a fase agrícola devido à considerável acumulação de sedimentos no interior dos canais. Com o início da fase de construções, grande quantidade de areia é levada para os sistemas de canais e novos obstáculos de areia (barras fluviais) podem se interpor ao leito do canal. Se ocorrer o estabelecimento de vegetação sobre os obstáculos, os canais são estreitados, ou localmente terraços podem ser erodidos, acompanhado por um crescimento nas inundações e no estreitamento do canal. Com a construção de estradas e sistemas de esgotos, os sedimentos derivados do interflúvio decrescem quando a velocidade 
do escoamento superficial é crescente. Obstáculos do canal e vegetação podem ser removidos pelo aumento do fluxo de água. Com o tempo, a ausência de um suprimento de sedimento pode resultar na progressiva erosão das margens do canal sem a concomitante deposição.

A hipótese apresentada por Wolman acerca da diminuição do suprimento de sedimentos para o canal devido a um crescimento de uma área urbana, com o conseqüente aumento do escoamento superficial, desconsidera uma possível fase de reativação das atividades de construção derivadas de uma possível nova fase de expansão urbana, como as que ocorrem nas áreas periféricas de um centro urbano, sobretudo em países em desenvolvimento. A mobilização de grande quantidade de material é o principal efeito evidenciado a partir dos desmatamentos e posteriores instalações de campos de obras para edificação de construções.

Ebisemiju (1989) apresenta como hipótese de seu estudo as respostas dos fluxos fluviais para a urbanização da área de captação do interflúvio nos trópicos úmidos, sendo as principais uma redução na capacidade da corrente do canal e na eficiência hidráulica.

Tais hipóteses levam em consideração vários fatores naturais que atuam em zonas tropicais, dentre os quais: os altos índices de precipitação e a intensidade das chuvas; a sazonalidade com a conseqüente irregularidade dos índices de precipitação refletida sobre a densidade da drenagem ao longo do ano; a cobertura vegetal ripária como fator de estabilidade das margens e a ação preponderante do intemperismo químico como fator de produção de sedimentos em suspensão e solúveis, sendo esses de menor habilidade erosiva para os leitos e margens dos canais fluviais.

Acrescidos a esses fatores naturais, o meio urbano responde pela produção de variados objetos derivados do lixo produzido diariamente, destacando-se papéis, plásticos e garrafas, que levam a uma rápida diminuição da capacidade do canal, havendo uma menor habilidade dos canais para transmitir água e sedimento rapidamente, propiciando uma predisposição do estreitamento das planícies de inundação dos canais que atravessam trechos urbanos. 
Além do reconhecimento das diferenças sazonais entre as zonas temperadas e tropicais, Ebisemiju demonstra a partir dessas hipóteses que, apesar dos variados indicadores pluviométricos que, inicialmente, poderiam representar uma maior capacidade e eficiência dos canais, os mesmos fazem parte de um sistema complexo de interrelações entre os fatores do meio tropical que resulta justamente em um efeito adverso ao esperado, que seria um aumento na capacidade da corrente dos canais e conseqüentemente na eficiência hidráulica.

Whitlow e Gregory (1989) evidenciam que em áreas tropicais tem sido muito menos investigadas a natureza de mudanças nos canais fluviais e sua importância em áreas urbanizadas. A combinação de fortes e intensas chuvas (até $25 \mathrm{~mm} / \mathrm{h}$ ) com as cidades tropicais que tem considerável extensão física e no tamanho da população, sobretudo nos últimos 25 anos, e particularmente no continente africano, pode causar um ajuste substancial e modificações das redes de canais urbanos tropicais.

Sendo contemporâneo do estudo realizado por Ebisemiju (1989) na Nigéria, o trabalho de Whitlow e Gregory (1989) nas áreas de dambos no Zimbábue apresenta como hipótese a possibilidade de ajustes e modificações da dinâmica de canais fluviais a partir de alterações de ambientes outrora naturais, no caso os dambos, que passaram a sofrer intensa atuação derivada da expansão urbana.

Verifica-se que enquanto Ebisemiju apresenta como hipótese as possíveis alterações no interior dos canais fluviais, os autores em pauta ampliam as hipóteses considerando mudanças na rede de canais inseridos no ambiente pantanoso dos dambos.

No estudo realizado por Gregory, Davis e Dows (1992), os autores introduzem os efeitos das variações espaço-tempo através de medições de preenchimento de 40 seções transversais e da dinâmica do crescimento urbano verificada ao longo das décadas de 1930, 1950, 1960 e 1970 na área de Chandlers Ford que, teoricamente, deveria propiciar a partir da ampliação da área urbana na última década pesquisada o crescimento na incidência e magnitude das descargas de pico ao longo do riacho Monks, que por seu turno deveria afetar as dimensões do canal fluvial. 
Assim, se os efeitos de uma reativação urbana nos anos 1970 no escoamento superficial e nos processos do canal induzem ao alargamento do canal, então a capacidade do canal à jusante da área urbana deveria ser maior. Entretanto, a relação entre capacidade do canal e área de drenagem mostra um não consistente aumento à jusante na capacidade devido à urbanização, embora a capacidade do canal à jusante esteja claramente bem acima da linha de regressão. Apesar da avaliação espaço-tempo não ter claramente indicado a magnitude de mudança no canal no riacho Monks, estudos de reconhecimento de campo indicam que um ajuste considerável do canal tem acontecido.

\section{Conclusões dos Estudos}

Apesar da realização de um estudo anterior ao período de ápice do movimento ambientalista, que culminou com a Conferência de Estocolmo em 1972, o estudo de Wolmanjá evidenciava nas suas conclusões a percepção da complexidade do comportamento de um canal fluvial urbano e sua área de interflúvio alterada por atividades antrópicas (urbanas ou não).

O autor já demonstrava as preocupações da sociedade americana para com as mudanças na dinâmica dos canais com o reconhecimento do valor potencial das terras de várzea e mesmo de fundo dos rios para o uso de recreação, refletindo o esforço que teve início já no final da década de 60 para evitar os fluxos de canalizações urbanas com concreto ou outros materiais a fim de melhor preservar o ambiente ribeirinho nas cidades.

Apesar de apresentar as diversas vantagens da concretação dos canais, tais como: a rápida dispersão da drenagem da chuva, um potencial crescimento para a auto-limpeza, e menor custo de manutenção, Wolman (1967) reconhece que deve-se ter cuidados com os projetos que podem amenizar tais problemas, mas que em alguns casos é provável que a remoção de sedimentos e detritos e a contínua manutenção do canal seja requerida constantemente. Para Wolman (1967) é importante que planos alternativos para controle e uso dos rios sejam desenvolvidos de acordo com algum entendimento dos princípios de seu comportamento. 
Em Ebisemiju (1989) as conclusões a que chega o autor estão voltadas especificamente para as conseqüências da urbanização sobre a área de interflúvio, ao reconhecer que as alterações na área de uma bacia fluvial promovem uma rápida erosãodo leito do canal e os obstáculos dela derivados induzem à agradação do canal, inundações e o conseqüente desenvolvimento de planícies de inundação por acreção vertical e lateral do vale, bem como a redução da competência da corrente, da capacidade do canal e da eficiência hidráulica.

Percebe-se que o autor não cita ações necessárias à prevenção de mudanças na dinâmica fluvial, contudo uma grande contribuição de suas conclusões finais reside no fato do mesmo chamar a atenção para o fato de que a natureza das respostas do canal para a urbanização dependerá da localização da urbanização na rede do canal, bem como para a ênfase dada às inundações, consideradas uma conseqüência inevitável da urbanizaçãono desenvolvimento de cidades nos trópicos úmidos.

O estudo da área de dambo no Zimbábue realizado por Whitlow e Gregory (1989) conclui que a rede de canais de um rio em uma área urbana não assume simplesmente uma forma determinada pela drenagem das águas das chuvas. No caso do rio Avondale o modelo de fluxo que existia no fim do século XIX tem subseqüentemente sido modificado através de 5 vias:

1. Introdução de seções descontínuas no curso do canal que interligam permanentemente as áreas de dambo;

2. A gradual canalização de seções do canal do rio;

3. A gradual adição da drenagem de águas da chuva;

4. O alargamento da canalização especialmente onde o leito e margens não tem sido reforçados;

5. Mudanças pela erosão das margens induzidas pelos movimentos rotacionais das margens do canal à jusante da área urbana que têm levado ao crescimento recente da largura em mais de duas fases. 
O fato dos autores trabalharem uma área pantanosa, portanto de equilíbrio ecodinâmico bem mais complexo, sobre processo de urbanização, leva os mesmos a concluir que variadas alterações podem ser identificadas ao longo de quase um século de mudanças, dentre as quais: a diminuição das descargas de preenchimento à jusante da área urbana, que agora são menores que o dobro das descargas obtidas quando a bacia não era afetada pela drenagem das águas da chuva que escoa das áreas urbanizadas; e o aumento considerável da descarga de inundação.

O reconhecimento dos Dambos como aspectos importantes da rede de drenagem no Zimbábue e do plantio na savana tropical, é importante para o entendimento de como a degradação de tais áreas por meio de mecanismos de regulação pode afetar a hidrologia e a erosão do canal do rio Avondale nas áreas rurais e urbanas. Devido à complexidade da área no que se refere aos fatores que interagem na dinâmica do canal e interflúvio, conclui-se que as alterações derivadas da expansão urbana no último século não afetam apenas o curso fluvial do Avondale, inserido no perímetro urbano de Harare, mas que tais mudanças têm abrangência que extrapola os limites da cidade, tendo conseqüências também para as áreas rurais que, indiretamente, podem se refletir sobre a cidade no que diz respeito aos aspectos sócio-econômicos, por exemplo, por meio da diminuição da produção de alimentos cultivados.

Os autores concluem, ainda, que apesar de em muitas áreas do mundo a regulação de rios haver sido realizada por uma seqüência de freqüentes alterações não relacionadas, do ponto de vista espacial e mesmo temporal, o reconhecimento de possíveis conseqüências de tais regulações para as mudanças em um canal podem ser consideradas a partir de políticas públicas que levem ao desenvolvimento de projetos de gerenciamento e manejo, com vistas à prevenção de possíveis transtornos sócioeconômicos-ambientais.

Gregory, Davis e Dows (1992) concluem que o ajustamento de um canal, no caso o riacho Monks, devido à atividade humana (especificamente ligadas à urbanização) pode ocorrer em diferentes classes e ser espacialmente descontínuo e variável no tempo. Os autores se utilizaram de inúmeros indicadores para reconhecer que a variabilidade na forma do canal ocorre ao longo de várias seções analisadas, e 
que essa variabilidade também ocorre ao longo de canais que são alterados como um resultado de uma expansão da urbanização.

Evidencia-se ainda nas conclusões dos autores anteriormente citados a necessidade da inserção, quando do desenvolvimento de estratégias de gerenciamento de um rio, de projeções de possíveis mudanças que provavelmente ocorrerão ao longo do canal fluvial, bem como também das possíveis características dessas alterações e localização das mesmas no canal. A descontinuidade espacial e temporal de mudanças ao longo do trecho estudado do riacho Monks demonstra a complexidade e os variados fatores que podem influenciar as alterações dos elementos morfológicos de um canal fluvial.

\section{CONSIDERAÇÕES FINAIS}

A expansão urbana verificada nos últimos dois séculos tem proporcionado diversas alterações aos ambientes outrora naturais, desde impactos de abrangência espacial significativa como a poluição atmosférica, a mudanças de equilíbrio natural em ambientes mais restritos, como encostas interfluviais e calhas fluviais.

No caso de mudanças da dinâmica de canais fluviais, que podem ser de caráter direto ou indireto (Cunha, 1994), os efeitos dessas alterações podem ser transmitidos a longas distâncias, tanto à montante quanto à jusante de focos de mudanças, além disso, os estudos de Geomorfologia Fluvial Urbana nas últimas décadas do século XX constataram incertezas, derivadas dos variados fatores e graus de intensidade, quanto às respostas de um canal diante de modificações efetivadas diretamente no canal ou mesmo na bacia de captação.

A avaliação dos quatro estudos apresentados anteriormente leva-nos a constatar as evoluções verificadas em mais de duas décadas, quando preocupações iniciais com as conseqüências derivadas de alterações nas áreas de interflúvio (Wolman, 1967) deram margens a estudos diretamente no interior dos canais (Gregory, Davis e Dows, 1992), e abriram novos horizontes através de avaliações comparativas de comportamento de mudanças, verificadas, inclusive, em ambientes tropicais. 
Apesar de posições contemporâneas imediatistas quanto à resolução de problemas derivados de impactos em calhas fluviais, ou mesmo nas áreas de planícies aluviais por parte de planejadores e gestores,que visam gerenciar a dinâmica de rios, restaurar paisagens ribeirinhas, e mesmo contribuir para minimizar riscos (THORNDYCRAFT, BENITO e GREGORY, 2008), a leitura dos textos em questão acerca de impactos derivados de alterações no interior de canais fluviais ou mesmo em suas bacias de captação, demonstra como o tratamento de tais distúrbios na dinâmica natural tem causas e, conseqüentemente, resoluções complexas, o que demanda uma abordagem multidisciplinar, em que a participação da Geomorfologia Fluvial faz-se necessária, mas em concomitância com a Engenharia, Ecologia e Hidrologia (THORNE et. al., 1997).

Constituindo-se em importantes referenciais para o entendimento da complexidade das interrelações dos fatores que influenciam nos desequilíbrios dos sistemas fluviais, os textos de Wolman (1967), Ebisemiju (1989), Whitlow e Gregory (1989) e Gregory, Davis e Dows (1992) são precursores dos estudos voltados para a dinâmica fluvial em ambientes progressivamente afetados pela expansão urbana, sendo os mesmos ferramentas teóricas fundamentais para a formulação de projetos de planejamento e gestão de áreas ribeirinhas no interior de cidades que busquem o equilíbrio dinâmico entre os aspectos naturais e sócio-econômicos.

\section{REFERÊNCIAS}

ANA, Agência Nacional de Águas. Atlas Brasil: abastecimento urbano de água: resultados por estado. Brasília: ANA: Engecorps/Cobrape, 2010.

CUNHA, S. B. Geomorfologia Fluvial. In: GUERRA, A, J. T. E CUNHA, S. B. Geomorfologia: Uma atualização de bases e conceitos. Rio de Janeiro: Bertrand Brasil, p. 211-252. 1994.

CUNHA, S. B. e GUERRA, A. J. T. Degradação Ambiental. In: GUERRA, A, J. T. E CUNHA, S. B. Geomorfologia e Meio Ambiente. Rio de Janeiro: Bertrand Brasil. 337-374, p. 337-379. 1996.

EBISEMIJU, F. S. The Response to Headwater Stream Channels to Urbanization in the Humid Tropics. In: Hydrologycal Processes. vol. 3, p. 237-253. 1989.

GREGORY, K. J. Environmental effects of river channel changes. In: Regulated Rivers: Research and Management. 1, p. 358-363. 1987. 
GREGORY, K. J. The human role in changing river channels. In: Geomorphology. Vol. 79, p. 172-191. 2006.

GREGORY, K. J., DAVIS, R. J. e DOWS, P. W. Identification of River Channel Change to due to Urbanization. In: Applied Geography. Vol. 12, p. 299-318. 1992.

MAYHEW, S. Dictionary of Geography. 3 ed. Oxford University Press, 2004. 543 p.

THORNDYCRAFT, V. R., BENITO, G. e GRAGORY, K. J. Fluvial Geomorphology: Perspective on current status and methods. In: Geomorphology. Vol. 98(1), p. 2-12. 2008.

THORNE, C. R., NEWSON, M. D. e HEY, R. D. Application of applied fluvial geomorphology: Problems and potencial. In: THORNE, C. R., HEY, R. D e NEWSON, M. D. (Orgs.). Applied Fluvial Geomorphology in River Engineering Management. Wiley, Chischester, 365-370. 1997.

WHITLOW, J. R. e GREGORY, K. J. Changes in Urban Stream Channls in Zimbabwe. In: Regulated Rivers: Research and Management. Vol. 4, p. 27-42. 1989.

WOLman, M. G.A Cyclo of Sedimentation and Erosion in Urban River Channels. In: Geografiska Annaler. n. 49, p.385395. 1967. 